\title{
Sagittal Spinal and Pelvic Parameters in Patients With Scheuermann's Disease: A Preliminary Study
}

\author{
S. SAMUEL BEDERMAN, MD, PHD, FRCSC, ${ }^{1}$ SAIF FARHAN, MD ${ }^{2}$ XIAOBANG HU, MD, PHD, CCRP, ${ }^{3}$ \\ ISADOR H. LIEBERMAN, MD, MBA, FRCSC, ${ }^{3}$ THEODORE A. BELANGER, MD, ${ }^{4}$ ARIF MUSA, MS, ${ }^{5}$ \\ MARTIN C. EICHLER, MD 6 \\ ${ }^{I}$ Restore Orthopedics and Spine Center, St. Joseph Hospital, Orange, California, ${ }^{2}$ Department of Orthopedic Surgery, University of California Irvine Medical \\ Center, Orange, California, ${ }^{3}$ Department of Pathology, University of Texas Southwestern Medical Center, Dallas, Texas, ${ }^{4}$ Scoliosis and Spine Tumor Center, \\ Texas Back Institute, Texas Health Presbyterian Hospital Plano, Plano, Texas, ${ }^{5}$ School of Medicine, Wayne State University, Detroit, Michigan, ${ }^{6}$ Neurochirurgie \\ Fathi AG, Schachen 22, 5000 Aarau, Switzerland
}

\begin{abstract}
Background: Sagittal spinopelvic parameters remain poorly defined in patients with Scheuermann disease (SD). For example, although pelvic incidence (PI) should approximate lumbar lordosis (LL) by $10^{\circ}$, this is not true in patients with SD. This retrospective radiographic study was conducted to propose a new mathematical relationship between sagittal spinopelvic parameters in skeletally mature patients with SD.

Methods: The following formula $(\Delta)$ was proposed [(thoracic kyphosis $\left.-45^{\circ}\right)+($ thoracolumbar kyphosis $\left.\left.0^{\circ}\right)+(\mathrm{PI}-\mathrm{LL})= \pm 10^{\circ}\right]$ and validated with standard spino pelvic parameters in patients with skeletally mature SD without prior spine surgery at 2 centers between 2006 and 2015. The T1 pelvic angle (TPA) was used as a measure of global balance with normal maximum of $15^{\circ}$. Subgroup analysis was performed to compare $\Delta$ between balanced $\left(\mathrm{TPA} \leq 15^{\circ}\right)$ and unbalanced $\left(\mathrm{TPA}>15^{\circ}\right)$ patients with SD.

Results: In patients with SD $(\mathrm{n}=30)$, half were female $(\mathrm{n}=15)$, the average age was 39 years, and the average $\Delta$ was $2.4^{\circ}$. A significant correlation was discovered between $\Delta$ and both TPA $\left(R^{2}=0.75\right)$ and PI $\left(R^{2}=0.69\right)$. At TPA of $15^{\circ}$, average $\Delta$ was $9.2^{\circ}$. There was also a significant difference between balanced and unbalanced patients $\left(-8.7^{\circ} \pm 11.6^{\circ}\right.$ versus $\left.28.2^{\circ} \pm 19.7^{\circ}, P=.0003\right)$.

Conclusions: This study of a new formula $(\Delta)$ to evaluate global sagittal balance in patients with SD found that accounting for the kyphosis maintained $\Delta$ within $\pm 10^{\circ}$. Further study is planned to determine whether maintaining and/or restoring a normal $\Delta$ is associated with improved outcomes in patients with SD after surgery.
\end{abstract}

\section{Lumbar Spine}

Keywords: Scheuermann disease, Scheuermann kyphosis, spinopelvic parameters, sagittal balance, T1 pelvic angle, lumbar lordosis

\section{INTRODUCTION}

A structural kyphosis of the thoracic and thoracolumbar spine occurring in adolescence was first described by Scheuermann in 1920 and is the most common cause of sagittal plane deformity. ${ }^{1}$ Its etiology is poorly understood but likely multifactorial in nature. Classically, more than 2 adjacent vertebral bodies must be wedged $5^{\circ}$ or more and are characterized by endplate irregularities, vertebral body wedging, diminished anterior vertebral growth, and premature disc degeneration. The reported incidence is $1 \%-8 \%$ although this may be an underestimation due to being misinterpreted as a poor posture or overlooked radiographically at the thoracolumbar junction (TLJ). ${ }^{2,3}$
It has been recognized that maintaining and/or restoring sagittal spinopelvic balance plays a critical role in optimizing patients' outcome after spinal reconstruction surgeries and the concept of pelvic incidence (PI) as a fixed individual parameter plays a central role. ${ }^{4-6}$ In particular, PI could reliably predict lumbar lordotic curves in both normal and scoliotic populations. ${ }^{6}$ As a result, the PI was initially used to predict the lumbar lordosis (LL) needed in each individual to attain sagittal balance: $\left[\mathrm{LL}=\mathrm{PI}+9^{\circ}( \pm 9)\right]^{7,8}$ Later, the T1 pelvic angle (TPA), which accounts for both spinal inclination and pelvic tilt (PT) simultaneously, and is less affected by variations in standing compensation, was incorporated.

To maintain a balanced posture and a forward visualized gaze, the thoracic hyperkyphosis is 
commonly compensated with a nonstructural hyperlordosis of the lumbar and cervical spine in younger people with flexible spines. ${ }^{9-11}$ In degenerative cases, the lumbar spine gets more stiffened and loses its mobility. In this situation, other compensation mechanisms get more important as hip retroversion and knee flexion. ${ }^{11}$

However, sagittal spinopelvic parameters are still poorly defined in patients with Scheuermann disease (SD). To our knowledge, there is only 1 study by Jiang et $\mathrm{al}^{12}$ analyzing the sagittal profile in Scheuermann thoracolumbar kyphosis (TLK). Although this study found a significant correlation between the PI and LL, this was not observed in patients with thoracic kyphosis (TK). Therefore, excessive TK and/or TLK in SD are not reflected in pelvic parameters. This preliminary study was conducted to identify a statistically significant parameter representing the kyphosis at the TLJ that may improve prediction of the magnitude of LL in a mathematical relationship between sagittal spinopelvic parameters in patients with skeletally mature SD. We hypothesized that kyphosis in the thoracic or thoracolumbar region would account for the compensation in LL beyond what the PI would predict.

\section{MATERIALS AND METHODS}

After obtaining institutional review board approval, all patients with Scheuermann kyphosis at the 2 medical centers in the United States between January 2006 and July 2015 were retrospectively analyzed. In this study, SD was diagnosed on the basis of the following radiographic criterion: anterior vertebral wedging greater than $5^{\circ}$ involving 3 or more contiguous vertebrae. Patients who met the following inclusion criteria were selected for inclusion: (1) diagnosed with SD; (2) aged between 18 and 75 years; (3) with no prior history of spinal surgery; (4) with no diseases of hip joint or lower limbs. Patients who were positive for 1 of the following exclusion criterion were excluded from the study: (1) kyphosis originating from posture, trauma, and infection or ankylosing spondylitis; (2) an underlying neurological etiology for the spinal deformity.

\section{Radiographic Evaluation}

Radiographic parameters were measured from full-standing lateral radiographs with the subject in

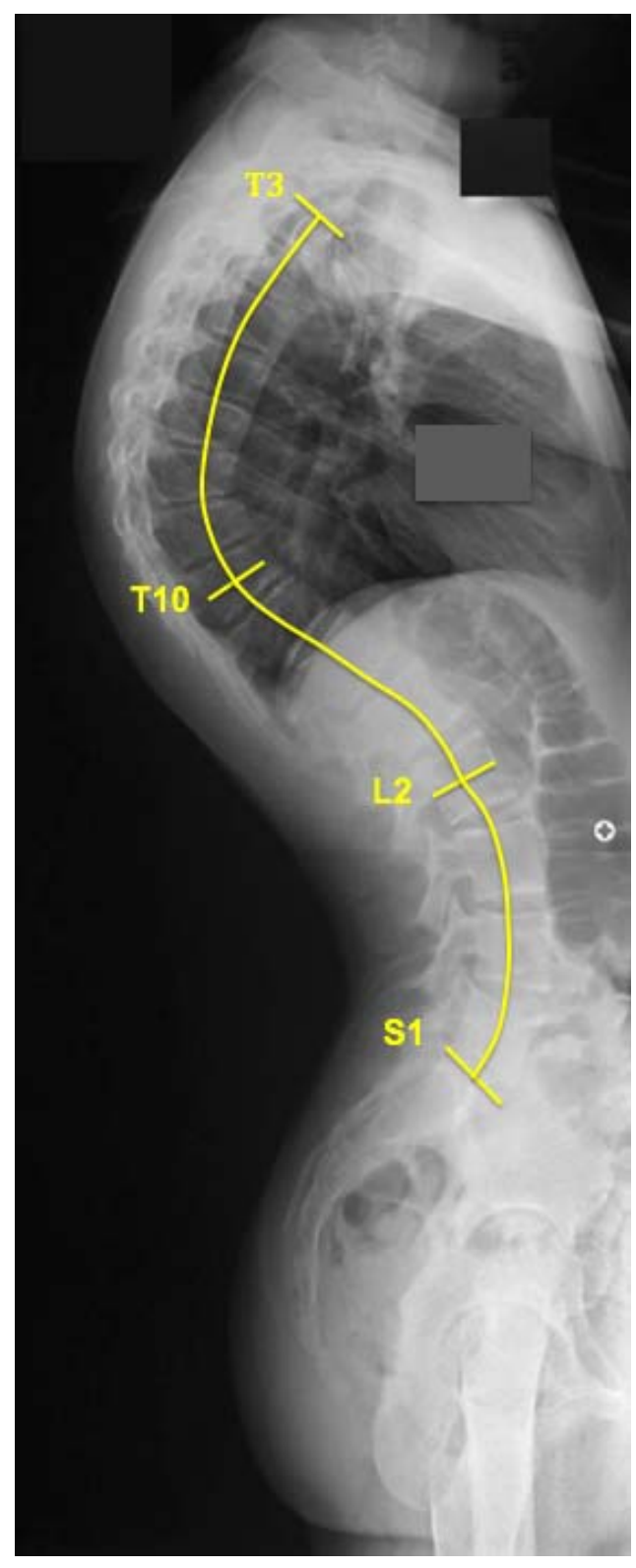

Figure 1. Measurements of spinal parameters in the sagittal plane: (1) thoracic kyphosis (TK) (superior endplate of T3-midbody of T10, angle $=$ TK); (2) thoracolumbar kyphosis (midbody of T10-midbody of L2); (3) lumbar lordosis $(\mathrm{LL})$ (midbody of L2-superior endplate of S1, angle $=\mathrm{LL}$ ).

a standardized position (knees and hips in full extension, arms forward directed at $90^{\circ}$ and resting on a support). ${ }^{13}$ Sagittal and frontal spinopelvic parameters were assessed using Surgimap (Nemaris Inc, New York, NY), a validated computer-based tool that enables quantitative measurements of the spine and pelvis. ${ }^{14,15}$

The following spinal parameters were measured: TK, TLK, and LL (Figure 1). The pelvic parameters measured included PI, PT, and sacral slope (SS) (Figure 2). We also measured the TPA, the angle between the center of the T1 vertebrae, midpoint of 


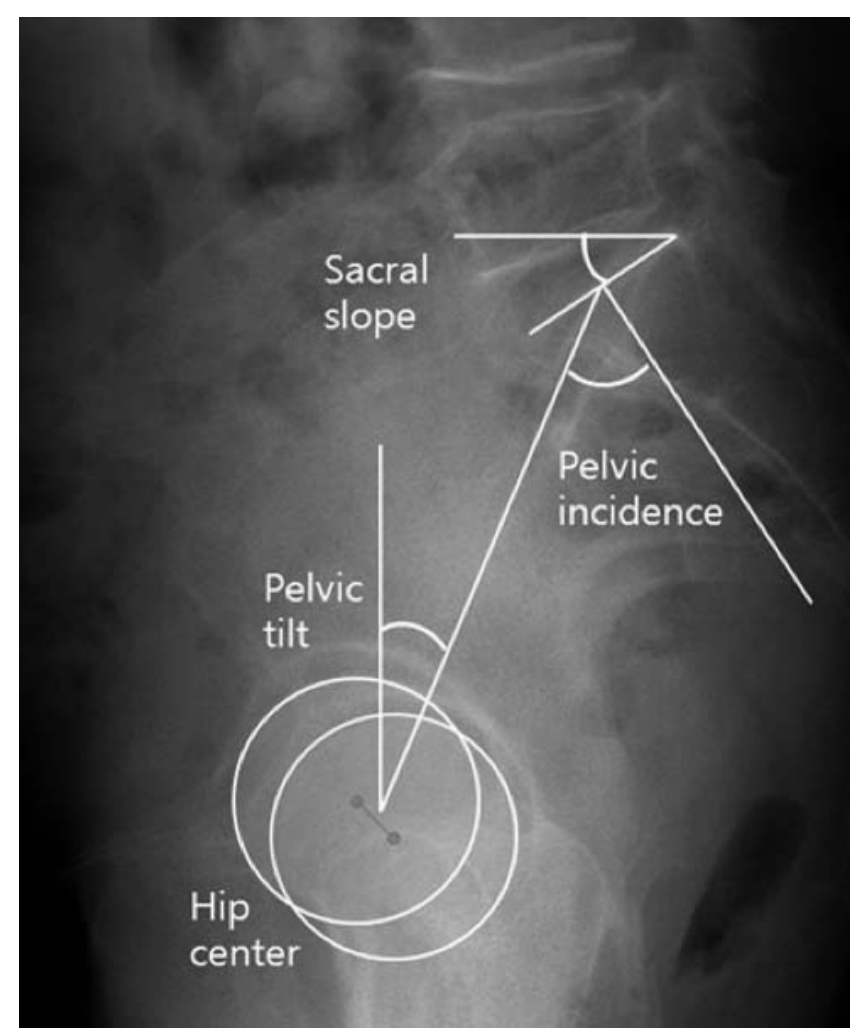

Figure 2. Measurements of pelvic parameters in the sagittal plane: (1) pelvic incidence (PI); (2) pelvic tilt (PT); (3) sacral slope (SS).

a line connecting the center of the hips, and the midpoint of the sacral endplate, which simultaneously describes spinal inclination and PT. ${ }^{16}$ In order to avoid overlap in Cobb angle measurements, we utilized mutually exclusive regions for TK, TLK, and LL. Due to wedging of vertebral bodies, we used the average between upper and lower endplates at the intercalary levels (ie, T10 and L2) to avoid angle overlap within the vertebral body (Figure 3).

TK was measured from the upper (cephalad) endplate of $\mathrm{T} 3$ to the mid body (average of upper and lower endplates) of T10, kyphosis at the thoracic lumbar junction from the mid body of T10 to the mid body of L2, and LL from the mid body of L2 to the superior endplate of S1 using the Cobb method. In the event that the S1 endplate was difficult to identify, an alternative technique for drawing the sacral endplate line was to construct a perpendicular line to the posterior vertebral bodyline of the sacrum. Additionally, the following pelvic parameters were measured:

- PI: the angle between a perpendicular line to the midpoint of the sacral endplate and the midpoint of a connecting line between the center of the hips.

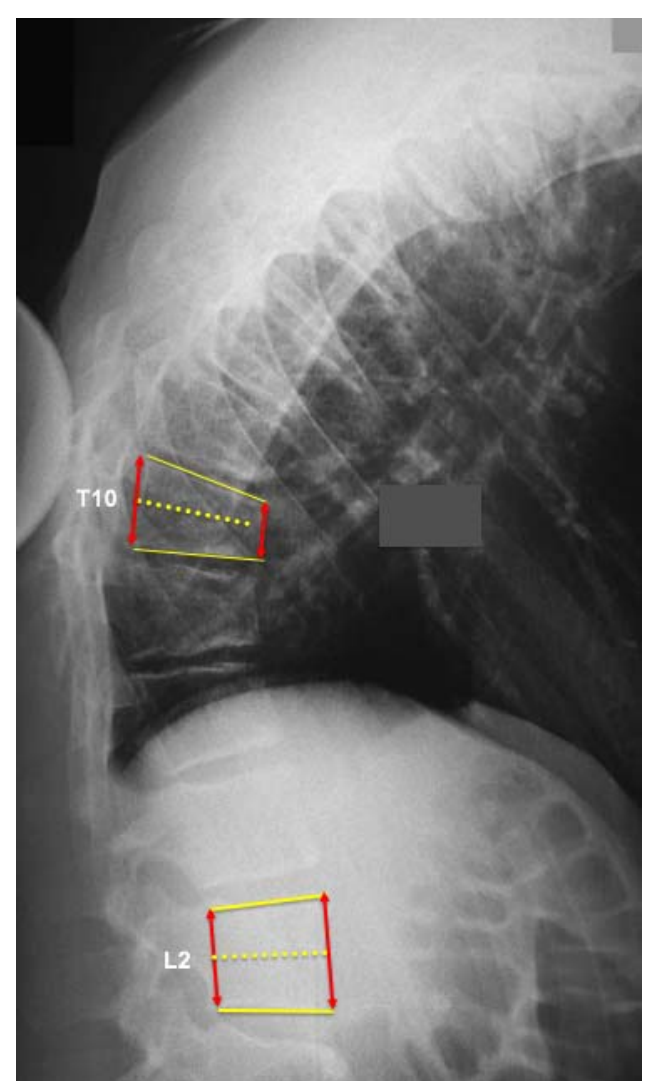

Figure 3. To avoid angle overlap, measurements were made using the average between the endplates for intercalary vertebrae such as T10 and L2.

- SS: the angle between sacral endplate and the horizontal line.

- PT: the angle between the midpoint of the sacral endplate, the midpoint of the connecting line of the center of hips, and a vertical line.

The following global sagittal parameters were measured:

- sagittal vertical axis: the distance between the gravity line falling from the center of the $\mathrm{C} 7$ vertebral body and the posterior edge of the sacral endplate.

- TPA: the angle between the line connecting the center of the $\mathrm{T} 1$ vertebral body and the femoral head and the line connecting the femoral head to the midpoint of the sacral endplate.

In order to properly account for changes in the lumbar spine in patients with Scheuermann kyphosis, beyond that which would be predicted by the PI in normal patients, we expanded on existing mathematical relationships. Because PI does not approximate LL in patients with SD, we hypothe- 
sized that the relationship would become clearer if areas of excessive kyphosis in either the thoracic spine or TLJ were accounted for. Thus, in the thoracic spine, we incorporated the radiographic findings of Rose et $\mathrm{al}^{17}$ who reported TK $<45^{\circ}$ and showed the greatest sensitivity in determining the individual LL needed in an ideal balanced spine (sagittal vertical axis $<5 \mathrm{~cm}$ ) using the following formula: $\mathrm{PI}-\mathrm{LL}+\mathrm{TK} \leq 45^{\circ}$. At the $\mathrm{TLJ}$, we made the assumption that it should be a sagittally neutral segment (approximately $0^{\circ}$ kyphosis). Notably, Schwab et $\mathrm{al}^{18}$ reported that a mismatch between PI - LL under $10^{\circ}$ is one of the key factors to predict a good clinical outcome in an ideal spinopelvic alignment in adult deformity surgery. In summary, we felt that the LL should approximate PI with the additional thoracic/TLK. Extrapolating on this work, we postulated that:

$$
\mathrm{LL}=\mathrm{PI}+\left(\mathrm{TK}-45^{\circ}\right)+\left(\mathrm{TLK}-0^{\circ}\right) .
$$

Or, equivalently, the mismatch, which should be $\pm 10^{\circ}$ if properly balanced, would be calculated as:

$$
\Delta=(\mathrm{PI}-\mathrm{LL})+\left(\mathrm{TK}-45^{\circ}\right)+\left(\mathrm{TLK}-0^{\circ}\right) .
$$

After calculating the proposed formula $(\Delta)$ for each patient, the strength of the relationship between $\Delta$ and TPA and PI was measured. The TPA was used as a measure of global balance with a normal maximum of $15^{\circ}$.

\section{Statistical Analysis}

Linear regression was used to measure the strength of the relationship between $\Delta$ and TPA and $\Delta$ and $\mathrm{PT}$, respectively. Pearson correlation analysis was used to identify relationships between our proposed formula $(\Delta)$ and both TPA and PT. TPA, in particular, has been described as a useful radiographic measure of global sagittal deformity that correlates with the Oswestry Disability Index. ${ }^{16}$ Given that Protopsaltis et al ${ }^{16}$ suggested a target TPA of $<14^{\circ}$ and Ryan et al ${ }^{19}$ reported TPA $<15.9^{\circ}$ for well-aligned, sagittally balanced adults, a subgroup analysis was conducted to compare patients with TPA $\leq 15^{\circ}$ (balanced) and those with TPA $>15^{\circ}$ (unbalanced). Mean $\Delta$ values were compared according to 2-sample $t$ test, unpaired, and assuming unequal variances. Statistical analyses was carried out using Microsoft Excel Version 14 (Redmond, WA). The level of significance was set at $P<.05$.

\section{RESULTS}

A total of 30 patients were included in this study (15 males, 15 females). The patients' mean age was 39 years old (range, 14-71). Of these patients, 21 had thoracic Scheuermann kyphosis (STK), and the remaining 9 had Scheuermann kyphosis of the thoracolumbar region (STLK). There were no statistically significant differences between the spinopelvic parameters of patients with STK and those with STLK at significance level of .05: TPA $\left(10.0^{\circ} \pm 12.4^{\circ}\right.$ versus $\left.12.2^{\circ} \pm 14.4^{\circ}, P=.674\right)$, PT $\left(14.5^{\circ} \pm 14.3^{\circ}\right.$ versus $\left.18.4^{\circ} \pm 14.1^{\circ}, P=.498\right)$, PI $\left(55.3^{\circ} \pm 22.0^{\circ}\right.$ versus $\left.44.1^{\circ} \pm 7.8^{\circ}, P=.153\right)$, and $\operatorname{LL}\left(65.0^{\circ} \pm 15.8^{\circ}\right.$ versus $\left.56.1^{\circ} \pm 26.2^{\circ}, P=.257\right)$. Patient demographic data and spinopelvic parameters are listed in Table 1.

We observed a statistically significant and strong correlation between $\Delta$ and both TPA $\left(R^{2}=0.75\right)$ and PT $\left(R^{2}=0.69\right)$. At the maximal normal TPA for a sagittal balanced adult $\left(15^{\circ}\right), \Delta$ yielded a maximum of $9.2^{\circ}$. The relationships between $\Delta$ and TPA and $\Delta$ and PT are demonstrated graphically in Figures 4 and 5, respectively.

Based on TPA of $15^{\circ}$ as the cutoff for sagittal balance, there were 21 patients in the balanced group, which consisted of 10 males and 11 females with a combined age of $34.2 \pm 16.0$ years. The unbalanced group included 4 males and 5 females aged $46.9 \pm 15.6$ years. Applying our mathematical relationship to the spinopelvic parameters of each group yielded a marked difference between $\Delta$ of the TPA $\leq 15^{\circ}$ group $(\overline{\mathrm{x}}=-8.8 ; s=11.5$; range: -28 to $11 ; 95 \%$ confidence interval [CI]: -14.0 to -3.5$)$ and $\Delta$ of the TPA $>15^{\circ}$ group $(\overline{\mathrm{x}}=22.2 ; s=19.7$; range: 6 to $74 ; 95 \%$ CI: 13.1 to 43.3$)$. The difference between mean $\Delta$ values was considered statistically significant $(P<.001) . \Delta$ values for the balanced and unbalanced groups are listed in Table 2.

\section{DISCUSSION}

Sagittal spinal deformity is a common and disabling condition and leads to a diminished health related quality of life. ${ }^{5,20,21}$ Sagittal imbalance and kyphosis may arise from degenerative processes, posttraumatic kyphosis, inflammatory arthropathies, iatrogenic flat back, and Scheuermann kyphosis. ${ }^{3}$ The incidence of SD is probably underestimated because of misdiagnosis with poor posture or may be radiographically overlooked in the TLJ. ${ }^{22}$ Currently, it remains unclear if excessive 
Table 1. Demographic characteristics and spinopelvic measurements.

\begin{tabular}{|c|c|c|c|c|c|c|c|c|}
\hline \multicolumn{3}{|c|}{ Demographics } & \multicolumn{4}{|c|}{ Spinopelvic Parameters } & \multicolumn{2}{|c|}{ Formulae } \\
\hline Age, y & Sex & Kyphosis & PI $\left(^{\circ}\right)$ & PT $\left(^{\circ}\right)$ & $\mathbf{L L}\left(^{\circ}\right)$ & TPA $\left(^{\circ}\right)$ & PI-LL $\left(^{\circ}\right)$ & $\Delta$ \\
\hline 18 & $\mathrm{~F}$ & STK & 12 & -10 & 34 & -10 & -20 & -28 \\
\hline 19 & $\mathrm{~F}$ & STK & 23 & -5 & 60 & -8 & -37 & -16 \\
\hline 55 & $\mathrm{~F}$ & STK & 31 & -3 & 52 & -4 & -21 & -21 \\
\hline 38 & M & STK & 40 & 10 & 61 & 6 & -21 & -15 \\
\hline 52 & M & STK & 40 & 11 & 46 & 7 & -6 & -7 \\
\hline 22 & M & STK & 44 & 11 & 64 & 9 & -20 & 1 \\
\hline 51 & $\mathrm{~F}$ & STK & 46 & 7 & 58 & -1 & -12 & -22 \\
\hline 23 & M & STK & 49 & 9 & 67 & 4 & -18 & -11 \\
\hline 29 & $\mathrm{M}$ & STK & 51 & 10 & 68 & 7 & -17 & 6 \\
\hline 21 & $\mathrm{~F}$ & STK & 52 & 25 & 53 & 16 & -1 & 23 \\
\hline 35 & M & STK & 52 & 12 & 55 & 11 & -3 & 3 \\
\hline 30 & $\mathrm{~F}$ & STK & 53 & 14 & 55 & 5 & -2 & -6 \\
\hline 30 & $\mathrm{~F}$ & STK & 53 & 19 & 64 & 17 & -11 & 23 \\
\hline 40 & $\mathrm{~F}$ & STK & 58 & 10 & 67 & 9 & -9 & 5 \\
\hline 18 & M & STK & 61 & 5 & 74 & -5 & -13 & -12 \\
\hline 45 & M & STK & 67 & 23 & 66 & 24 & 1 & 17 \\
\hline 71 & $\mathrm{~F}$ & STK & 67 & 10 & 80 & 14 & -13 & 11 \\
\hline 14 & $\mathrm{~F}$ & STK & 83 & 20 & 85 & 15 & -2 & 0 \\
\hline 55 & M & STK & 87 & 44 & 59 & 32 & -28 & 31 \\
\hline 60 & $\mathrm{~F}$ & STK & 92 & 41 & 102 & 32 & -10 & 74 \\
\hline 71 & M & STK & 100 & 41 & 96 & 30 & -4 & 13 \\
\hline $\bar{x} \pm s$ & & & $55.3 \pm 22.0$ & $14.5 \pm 14.3$ & $65.0 \pm 15.8$ & $10.0 \pm 12.4$ & $-12.7 \pm 9.8$ & $3.3 \pm 22.9$ \\
\hline 18 & M & STLK & 34 & 10 & 66 & 7 & -32 & -2 \\
\hline 20 & $\mathrm{~F}$ & STLK & 34 & -1 & 80 & -6 & -46 & -18 \\
\hline 55 & $\mathrm{~F}$ & STLK & 41 & 18 & 57 & 12 & -16 & 5 \\
\hline 24 & M & STLK & 42 & 11 & 72 & 3 & -30 & -12 \\
\hline 50 & $\mathrm{~F}$ & STLK & 44 & 40 & -8 & 38 & 52 & 30 \\
\hline 36 & M & STLK & 45 & 20 & 45 & 17 & 0 & 6 \\
\hline 43 & $\mathrm{~F}$ & STLK & 46 & 11 & 70 & 0 & -24 & -24 \\
\hline 44 & M & STLK & 54 & 15 & 68 & 8 & 14 & -21 \\
\hline 54 & $\mathrm{~F}$ & STLK & 57 & 42 & 55 & 31 & 2 & 37 \\
\hline $\bar{x} \pm s$ & & & $44.1 \pm 7.8$ & $18.4 \pm 14.1$ & $56.1 \pm 26.2$ & $12.2 \pm 14.4$ & $-8.9 \pm 29.8$ & $0.1 \pm 21.8$ \\
\hline
\end{tabular}

Abbreviations: STK, Scheuermann thoracic kyphosis; STLK, Scheuermann thoracolumbar kyphosis; PI, pelvic incidence; PT, pelvic tilt; LL, lumbar lordosis; TPA, T1 pelvic angle; $\overline{\mathrm{x}}$, mean; s, standard deviation.

kyphosis in the thoracic spine or TLJ should be reflected in LL prediction, which may have implications for surgical planning. Several studies have shown mathematical relationships between sagittal

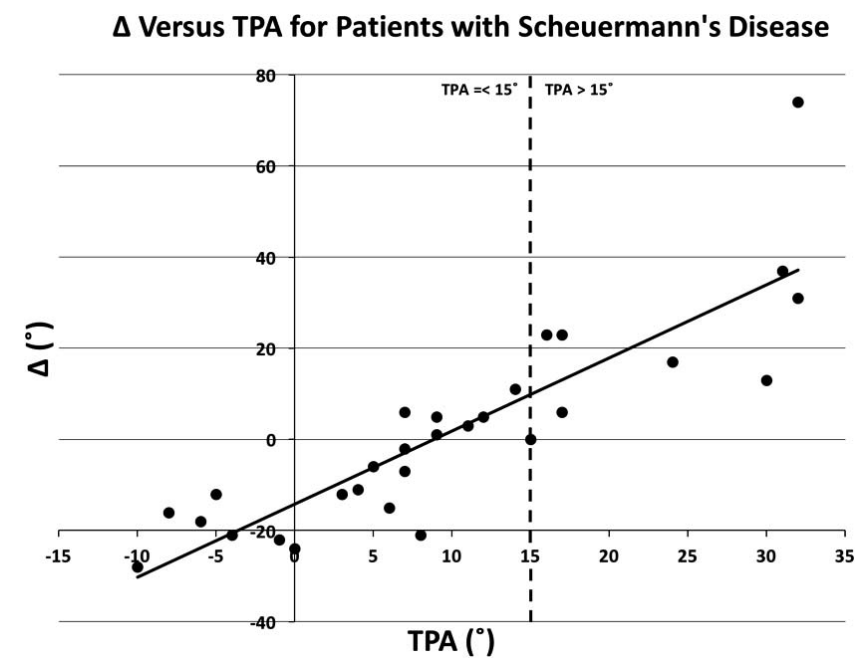

Figure 4. Graphical representation of the relationship between $\Delta\left({ }^{\circ}\right)$ and T1 pelvic angle (TPA) $\left({ }^{\circ}\right)$ plotted with regression line given by equation $y=1.6073 x-14.25\left(R^{2}=0.7558\right)$. balance and lumbar, thoracic, and pelvic parameters in adult deformities. Different studies about Scheuermann kyphosis question these relationships especially between PI and LL, whereas these 2 parameters have been shown to be key factors to account for in achieving good clinical results. ${ }^{18,23}$ On the other hand, Ashraf et $\mathrm{al}^{3}$ and Cahill et $\mathrm{al}^{24}$ showed in their studies that LL is driven by hyperkyphosis elsewhere. The latter suggest that the lumbar spine serves as a sagittal buffer between the pelvis and thoracic spine.

In patients with SD with low PI, several authors have reported a higher LL compared with healthy individuals. ${ }^{12,22,25,26}$ In a recently published study, Tyrakowski et al $^{26}$ could not find any significant difference in sagittal spinopelvic parameters between skeletally immature and mature subjects with SD and also confirmed low PI in adults with SD. Thus, in contrary to reported increasing PIs during childhood and adolescence in SD, PI seems to remain constant in skeletal maturity but low compared with a healthy "normal" population. ${ }^{27-29}$ 


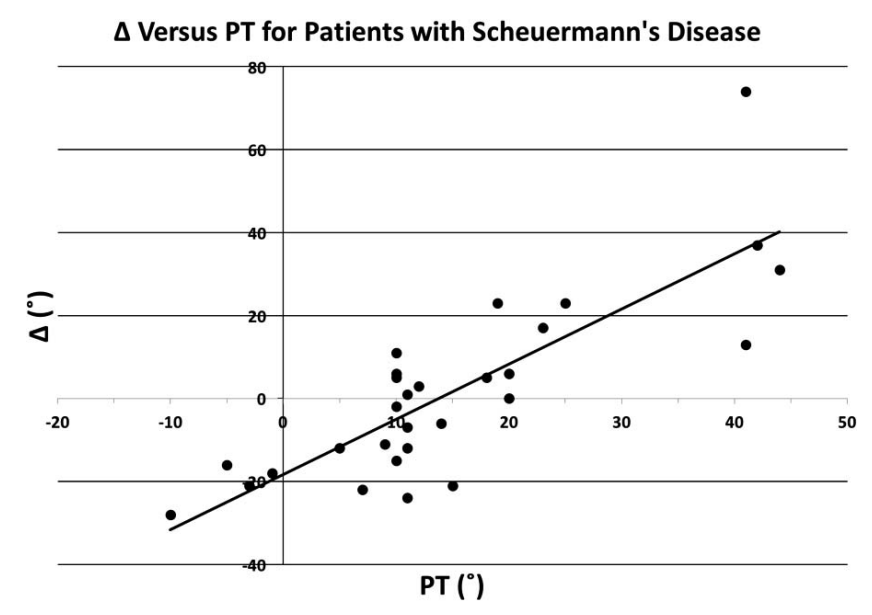

Figure 5. Graphical representation of the relationship between $\Delta\left(^{\circ}\right)$ and pelvic tilt $(\mathrm{PT})\left(^{\circ}\right)$ plotted with regression line given by equation $y=1.328 x-18.311$ $\left(R^{2}=0.67217\right)$.

Tyrakowski et $\mathrm{al}^{26}$ interpreted their low PIs as a limitation to an increasing PT. They postulate that hyperkyphosis is compensated by hyperlordosis. If this compensatory mechanism is exhausted, the pelvis will tilt posteriorly to decrease SS. With a fixed PI, PT will increase and leads to an ergonomically and biomechanically disadvantageous situation. They suspect a modification of the pelvis morphology (PI), so the increased PT is prevented. Thus, decreasing the PI could compensate for a low SS without changing PT.

Loder $^{25}$ investigated the sagittal profiles of Scheuermann TK and found an average increased lordosis of $71^{\circ}$. Similarly, Jansen et $\mathrm{al}^{9}$ and Lowe et $\mathrm{al}^{22}$ discovered significantly increased LL in Scheuermann TK with an average LL of $72^{\circ}$ and $75^{\circ}$, respectively. $\operatorname{Loder}^{25}$ and Lowe et $\mathrm{al}^{22}$ also showed a negative sagittal balance due to the hyperlordosis in Scheuermann kyphosis demonstrating a need for a compensation mechanism in a well-balanced spine. Furthermore, Jansen et $\mathrm{al}^{9}$ reported a significant correlation between TK and LL, which was confirmed by Jiang et $\mathrm{al}^{12}$ in a later study with strong correlation coefficient of 0.79 .

To maintain a balanced posture and a forward visualized gaze, the thoracic hyperkyphosis is commonly compensated with a nonstructural hyperlordosis of the lumbar and cervical spine in younger people with flexible spines. ${ }^{9-11,25}$ In degenerative cases, the lumbar spine stiffens and loses its mobility. In this situation, other compensation mechanisms, such as hip retroversion and knee flexion, become more important. ${ }^{11}$ Compensation mechanisms differ in thoracic hyperkyphosis and
Table 2. Differences in $\Delta$ according to TPA.

\begin{tabular}{rrrrrrrc}
\hline & \multicolumn{8}{c}{$\Delta$} \\
\cline { 2 - 7 } TPA $\left({ }^{\circ}\right)$ & \multicolumn{1}{c}{$\bar{x}$} & \multicolumn{1}{c}{$\boldsymbol{s}$} & \multicolumn{1}{c}{ Range } & $\mathbf{9 5 \%} \mathbf{C I}$ & \multicolumn{1}{c}{$\boldsymbol{P}$} & $\boldsymbol{P}$ \\
\hline$\leq 15$ & 8.8 & 11.5 & -28 to 11 & -14.0 to -3.5 & 6.5 & $<.0001$ \\
$>15$ & 28.2 & 19.7 & 6 to 74 & 13.1 to 43.3 & &
\end{tabular}

Abbreviations: TPA, T1 pelvic angle; $\bar{x}$, mean; s, standard deviation; CI, confidence interval.

TLK with remaining flexibility in the thoracic spine. $^{11,12}$

Jiang et $\mathrm{al}^{12}$ was the first to describe a difference in thoracolumbar and thoracic Scheuermann kyphosis spinopelvic parameters. TK and LL were significantly increased in STK cases when compared with STLK and the healthy control group. These differences may be due to the rigid kyphosis followed by compensation mechanism in the upper and lower adjacent levels with hyper lumbar and cervical hyperlordosis to maintain a balanced posture and horizontal gaze. On the other hand, these same authors showed a greater influence of STLK to the pelvis indicated by lower PI than in STK. Because the apex is lower in the STLK, there are often more segments in the upper thoracic spine, which could compensate for the hyperkyphosis. Therefore, the lumbar hyperlordosis was less prevalent than in STKs in the study by Jiang et al. As there is less room for correction in the lumbar spine because of the lower PI, STLK tend to compensate earlier over the pelvic retroversion if the thoracic hypokyphosis and lumbar hyperlordosis is exhausted. This indicates that the TLJ and TK must be analyzed separately, which our relationship does, to correctly address the different compensation mechanism in STK and STLK.

Notably, Jansen et $\mathrm{al}^{9}$ showed a correlation between LL and TK before and after corrective surgery for TK in SD and decrease of LL after surgery occurs mainly in the upper segments of the lumbar spine. Therefore, the amount of correction should also aim to normalize lordosis determined by PI. Ultimately, our findings illustrate how the excessive LL may represent the body's compensation for Scheuermann kyphosis. Furthermore, our mathematical description of spinal and pelvic parameters in patients with SD with thoracic or TLK may be useful for correction of Scheuermann kyphosis, though further testing is necessary to evaluate the usefulness of the proposed formula in surgical planning. 


\section{Limitations}

Our study has several limitations. Although we retrospectively reviewed a small sample, the number of patients was comparable with those of previous studies. ${ }^{12,30}$ Second, this is a cross-sectional radiographic study of adolescents and adults. In most of the studies about spinopelvic parameters in SD, the investigated population consisted of adolescents. As Tyrakowski et $\mathrm{al}^{30}$ showed no change in pelvic parameters in the maturity of the pelvis, values could be compared without any negative influences. All patients we included presented to our clinic because of disability and pain. Because these patients may have exhibited sagittal decompensation, we accounted for sagittal imbalance by evaluating the TPA as a validated parameter of global sagittal balance, which correlates with healthrelated outcomes. Finally, despite recent studies suggesting the use of TPA to evaluate sagittal balance, additional research is required to confirm how to evaluate and define sagittal balance in patients with Scheuermann kyphosis.

\section{CONCLUSION}

Our preliminary results show that excessive LL beyond what would be predicted by PI is comparable with excessive kyphosis in SD. Our relationship, $\left(\mathrm{TK}-45^{\circ}\right)+\left(\mathrm{TLK}-0^{\circ}\right)+(\mathrm{PI}-\mathrm{LL})$ maintained within $\pm 10^{\circ}$, is a valuable formula to evaluate the global sagittal balance in patients with skeletally mature SD. Further study is underway to evaluate if maintaining and/or restoring a normal $\Delta$ is associated with better clinical outcomes in patients with SD who were operated for lumbar degenerative diseases.

\section{REFERENCES}

1. Scheuermann HW. The classic: kyphosis dorsalis juvenilis. Clin Orthop Relat Res. 1977;(128):5-7.

2. Arlet V, Schlenzka D. Scheuermann's kyphosis: surgical management. Eur Spine J. 2005;14(9):817-827.

3. Ashraf A, Noelle Larson A, Polly DW, et al. Change in sagittal plane alignment following surgery for Scheuermann's kyphosis. Spine Deform. 2014;2(5):404-409.

4. Glassman SD, Berven S, Bridwell K, et al. Correlation of radiographic parameters and clinical symptoms in adult scoliosis. Spine (Phila Pa 1976). 2005;30(6):682-688.

5. Glassman SD, Bridwell K, Dimar JR, et al. The impact of positive sagittal balance in adult spinal deformity. Spine (Phila Pa 1976). 2005;30(18):2024-2029.

6. Legaye J, Duval-Beaupere G, Hecquet J, et al. Pelvic incidence: a fundamental pelvic parameter for three-dimension- al regulation of spinal sagittal curves. Eur Spine J. 1998;7(2):99103.

7. Boulay C, Tardieu C, Hecquet J, et al. Sagittal alignment of spine and pelvis regulated by pelvic incidence: standard values and prediction of lordosis. Eur Spine J. 2006;15(4):415422.

8. Schwab F, Lafage V, Patel A, et al. Sagittal plane considerations and the pelvis in the adult patient. Spine (Phila Pa 1976). 2009;34(17):1828-1833.

9. Jansen RC, van Rhijn LW, van Ooij A. Predictable correction of the unfused lumbar lordosis after thoracic correction and fusion in Scheuermann kyphosis. Spine (Phila Pa 1976). 2006;31(11):1227-1231.

10. Hellsing E, Reigo T, McWilliam J, et al. Cervical and lumbar lordosis and thoracic kyphosis in 8, 11, and 15-year-old children. Eur J Orthod. 1987;9(2):129-138.

11. Barrey C, Roussouly P, Le Huec JC, et al. Compensatory mechanisms contributing to keep the sagittal balance of the spine. Eur Spine J. 2013;22(suppl 6):S834-S841.

12. Jiang L, Qiu Y, Xu L, et al. Sagittal spinopelvic alignment in adolescents associated with Scheuermann's kyphosis: a comparison with normal population. Eur Spine J. 2014;23(7):1420-1426.

13. OBrien MF, Kuklo TR, Blanke KM, et al. Radiographic measurement manual [Scoliosis Research Society website]. 2008. www.srs.org/professionals/online-education-and-resourc es/radiographic-measurement-manual. Accessed October 26, 2016.

14. Akbar M, Terran J, Ames CP, et al. Use of Surgimap Spine in sagittal plane analysis, osteotomy planning, and correction calculation. Neurosurg Clin N Am. 2013;24(2):163172.

15. Lafage R, Ferrero E, Henry JK, et al. Validation of a new computer-assisted tool to measure spino-pelvic parameters. Spine J. 2015;15(12):2493-2502.

16. Protopsaltis T, Schwab F, Ryan DJ, et al. The T1 pelvic angle, a novel radiographic measure of global sagittal deformity, accounts for both spinal inclination and pelvic tilt and correlates with health-related quality of life. $J$ Bone Joint Surg Am. 2014;96(19):1631-1640.

17. Rose PS, Bridwell KH, Lenke LG, et al. Role of pelvic incidence, thoracic kyphosis, and patient factors on sagittal plane correction following pedicle subtraction osteotomy. Spine (Phila Pa 1976). 2009;34(8):785-791.

18. Schwab FJ, Blondel B, Bess S, et al. Radiographical spinopelvic parameters and disability in the setting of adult spinal deformity: a prospective multicenter analysis. Spine (Phila Pa 1976). 2013;38(13):E803-E812.

19. Ryan DJ, Protopsaltis TS, Ames CP, et al. T1 pelvic angle (TPA) effectively evaluates sagittal deformity and assesses radiographical surgical outcomes longitudinally. Spine (Phila Pa 1976). 2014;39(15):1203-1210.

20. Lafage V, Schwab F, Patel A, et al. Pelvic tilt and truncal inclination: two key radiographic parameters in the setting of adults with spinal deformity. Spine (Phila Pa 1976). 2009;34(17):E599-E606.

21. Schwab F, Patel A, Ungar B, et al. Adult spinal deformity-postoperative standing imbalance: how much can you tolerate? An overview of key parameters in assessing 
alignment and planning. Spine (Phila Pa 1976). 2010;35(25):2224-2231.

22. Lowe TG, Line BG. Evidence based medicine: analysis of Scheuermann kyphosis. Spine (Phila Pa 1976). 2007;32(19 suppl):S115-S119.

23. Rothenfluh DA, Mueller DA, Rothenfluh E, et al. Pelvic incidence-lumbar lordosis mismatch predisposes to adjacent segment disease after lumbar spinal fusion. Eur Spine J. 2015;24(6):1251-1258.

24. Cahill PJ, Steiner CD, Dakwar E, et al. Sagittal spinopelvic parameters in Scheuermann's kyphosis: a preliminary study. Spine Deform. 2015;3(3):267-271.

25. Loder RT. The sagittal profile of the cervical and lumbosacral spine in Scheuermann thoracic kyphosis. J Spinal Disord. 2001;14(3):226-231.

26. Tyrakowski M, Janusz P, Mardjetko S, et al. Comparison of radiographic sagittal spinopelvic alignment between skeletally immature and skeletally mature individuals with Scheuermann's disease. Eur Spine J. 2015;24(6):1237-1243.

27. Mangione P, Gomez D, Senegas J. Study of the course of the incidence angle during growth. Eur Spine J. 1997;6(3):163167.

28. Marty C, Boisaubert B, Descamps H, et al. The sagittal anatomy of the sacrum among young adults, infants, and spondylolisthesis patients. Eur Spine J. 2002;11(2):119-125.

29. Vrtovec T, Janssen MM, Likar B, et al. A review of methods for evaluating the quantitative parameters of sagittal pelvic alignment. Spine J. 2012;12(5):433-446.

30. Tyrakowski M, Mardjetko S, Siemionow K. Radiographic spinopelvic parameters in skeletally mature patients with Scheuermann disease. Spine (Phila Pa 1976). 2014;39(18):E1080-E1085.

Disclosures and COI: The authors received no funding for this study and report no conflicts of interest. The institutional review boards of the University of California Irvine and Texas Back Institute have provided approval for this study. Patient confidentiality has been protected according to the US Health Insurance Portability and Accountability Act (HIPAA) and in accordance to the tenets established by the Declaration of Helsinki for human subjects.

Corresponding Author: Martin C. Eichler, MD, Kanton St. Gallen, Rorschacherstr. 95, 9007 St. Gallen, Switzerland. Phone: +1 (949) 903-4680; Fax: +4 (171) 494-6341; Email: martin.eichler@ kssg.ch.

Published 31 December 2019

This manuscript is generously published free of charge by ISASS, the International Society for the Advancement of Spine Surgery. Copyright (C) 2019 ISASS. To see more or order reprints or permissions, see http://ijssurgery.com. 